BMJ Open Diabetes Research $\&$ Care

\title{
Comparison of weight-based insulin titration (WIT) and glucose-based insulin titration using basal-bolus algorithm in hospitalized patients with type 2 diabetes: a multicenter, randomized, clinical study
}

\author{
Xiaodan Zhang, ${ }^{1}$ Tong Zhang, ${ }^{2}$ Guangda Xiang (D) , ${ }^{3}$ Wenbo Wang, ${ }^{4}$ Yanli Li, ${ }^{1}$ \\ Tao Du, ${ }^{1}$ Yunjuan Zhao, ${ }^{1}$ Singla Sethiel Mosha, ${ }^{1}$ Wangen Li (D) ${ }^{1}$
}

\begin{abstract}
To cite: Zhang X, Zhang T, Xiang $\mathrm{G}$, et al. Comparison of weight-based insulin titration (WIT) and glucosebased insulin titration using basal-bolus algorithm in hospitalized patients with type 2 diabetes: a multicenter, randomized, clinical study. BMJ Open Diab Res Care 2020;8:e001261. doi:10.1136/ bmjdrc-2020-001261
\end{abstract}

Received 17 February 2020 Revised 26 July 2020 Accepted 30 July 2020

Check for updates

(c) Author(s) (or their employer(s)) 2020. Re-use permitted under CC BY-NC. No commercial re-use. See rights and permissions. Published by BMJ.

${ }^{1}$ Department of Endocrinology, The Second Affiliated Hospital of Guangzhou Medical University, Guangzhou, China ${ }^{2}$ Department of Endocrinology, The Third Affiliated Hospital of Southern Medical University, Guangzhou, China

${ }^{3}$ Department of Endocrinology, Wuhan General Hospital of Chinese People's Liberation Army, Wuhan, China ${ }^{4}$ Department of Endocrinology, Peking University Shougang Hospital, Beijing, China

Correspondence to Dr Wangen Li; liwg660@126.com

\section{ABSTRACT}

Introduction Subcutaneous administration of insulin is the preferred method for achieving glucose control in noncritically ill patients with diabetes. Glucose-based titration protocols were widely applied in clinical practice. However, most of these algorithms are experience-based and there is considerable variability and complexity. This study aimed to compare the effectiveness and safety of a weight-based insulin titration algorithm versus glucose-based algorithm in hospitalized patients with type 2 diabetes mellitus (T2DM). Research design and methods This randomized clinical trial was carried out at four centers in the South, Central and North China. Inpatients with T2DM were randomly assigned (1:1) to receive weight-based and glucose-based insulin titration algorithms. The primary outcome was the length of time for reaching blood glucose (BG) targets (fasting BG (FBG) and 2-hour postprandial BG (2hBG) after three meals). The secondary outcome included insulin dose for achieving glycemic control and the incidence of hypoglycemia during hospitalization.

Results Between January 2016 and June 2019, 780 patients were screened, and 575 completed the trial (283 in the weight-based group and 292 in the glucose-based group). The lengths of time for reaching BG targets at four time points were comparable between two groups. FBG reached targets within 3 days and $2 \mathrm{hBG}$ after three meals within 4 days. There is no significant difference in insulin doses between two groups at the end of the study. The total daily dosage was about $1 \mathrm{unit} / \mathrm{kg} / \mathrm{day}$, and the ratio of basal-to-bolus was about 2:3 in both groups. The incidence of hypoglycemia was similar in both groups, and severe hypoglycemia was not detected in either of the groups.

Conclusions Weight-based insulin titration algorithm is equally effective and safe in hospitalized patients with T2DM compared with glucose-based algorithm.

Trial registration number NCT03220919.

\section{INTRODUCTION}

Inpatient hyperglycemia is associated with adverse patient outcomes. Scheduled

\section{Significance of this study}

What is already known about this subject?

- Scheduled subcutaneous administration of insulin is the preferred way for achieving and maintaining glucose control in non-critically ill patients with diabetes.

- Most insulin titration protocols are glucose-based and are complex to execute.

What are the new findings?

- A weight-based insulin titration algorithm has been designed.

- The new protocol is proved to be equally effective and safe in hospitalized patients with type 2 diabetes compared with classical glucose-based algorithm.

How might these results change the focus of research or clinical practice?

- The study provides a new insulin titration method for achieving glucose control.

subcutaneous administration of insulin is the preferred method for achieving and maintaining glucose control in non-critically ill patients with diabetes or stress hyperglycemia. ${ }^{1}$ Basal-bolus insulin (BBI) protocol is recommended by the American Association of Clinical Endocrinologists (AACE) and American Diabetes Association (ADA). The traditional sliding scale insulin (SSI) is found to be ineffective and is discouraged. ${ }^{1}$ However, SSI continues to be a common practice, even in the most prestigious teaching hospitals, ${ }^{23}$ owing to its convenience and simplicity. ${ }^{4}$ BBI requires basal, bolus and correction insulin. The inconvenience and complexity of this approach has limited its acceptance among physicians. ${ }^{6}$ Thus, we tried to seek an alternative. 
Except for the insulin titration algorithm based on glycemic level, there is another group of titration protocols based on the percentage of current insulin dose. Although the former is widely used, the latter is also used for long-acting, ${ }^{7-9}$ premixed $^{10}$ and short-acting insulin. ${ }^{8-10}$ Interestingly, these two groups of algorithms are conflicting. The former leads to a decrease in the titration dose, while the latter leads to an increase. Given that both are acceptable, it is hypothesized that a fixeddose titration algorithm is reasonable.

In many clinical trials involving inpatients, insulin initiation was usually expressed as unit $/ \mathrm{kg}$ (body weight), as recommended by ADA. ${ }^{11-15}$ Also, at the end of these studies, the insulin dose was also expressed as unit/kg, which included long-acting insulin detemir and glargine, ${ }^{11}{ }^{15-20}$ premixed human insulin $30 / 70^{15}$ and short-acting human insulin, aspart, lispro and glulisine. ${ }^{14-16}$ Then, why is insulin not titrated as unit $/ \mathrm{kg}$, that is, based on weight?

Previously, we have designed a weight-based titration algorithm for long-acting insulin (glargine or determir, $0.1 \mathrm{unit} / \mathrm{kg} /$ day), ${ }^{18}{ }^{19}$ which is simple and effective as the glucose-based algorithm. Since basal-to-bolus insulin secretion was about 1:1 in normal persons, and in the treatment of patients with type 2 diabetes mellitus (T2DM),${ }^{21}$ we presumed that bolus insulin could also be titrated based on the body weight. The aim of this study was to investigate the effectiveness and safety of a weightbased insulin titration algorithm in hospitalized patients with T2DM.

\section{DESIGN AND METHOD}

\section{Participants}

This multicenter, randomized, controlled prospective study was conducted at the Department of Endocrinology in four centers (South China: The Second Affiliated Hospital of Guangzhou Medical University, The Third Affiliated Hospital of Southern Medical University; Central China: Wuhan General Hospital of Guangzhou Command; North China: Shougang Hospital of Peking University) from January 2016 to June 2019.

\section{Inclusion/Exclusion criteria}

Patients between the ages of 18 and 75 years, who were previously or newly diagnosed with T2DM, with random blood glucose (BG) $>10.0 \mathrm{mmol} / \mathrm{L}$ before admission were screened for the present study.

Patients were excluded if they met one of the following criteria: (1) receiving insulin therapy at a daily dose $>0.4$ unit $/ \mathrm{kg}$ at home before admission; (ii) unable to eat; (iii) receiving corticosteroid therapy; (iv) renal insufficiency (plasma creatinine concentration $\geq 130 \mu \mathrm{mol} / \mathrm{L}$ ) or liver insufficiency (aspartate aminotransferase (AST) or alanine aminotransferase (ALT) concentration ztwofold of references); (v) pregnancy; (vi) with previous or current history of malignant tumors.

\section{Randomization}

Randomization codes were generated using a computer program (SPSS V.16.0). Patients were randomly assigned (1:1) to each of the two treatment groups on the first day of admission at the four medical centers. Neither patients nor investigators were masked to treatment allocation.

\section{Procedures}

Basal-bolus (without correction) algorithm consisting of a subcutaneous injection of insulin glargine (SanofiAventis Deutschland GmbH, Frankfurt, Germany) at bedtime and subcutaneous injections of insulin aspart (Novo Nordisk, Bagsværd, Denmark) before each of three meals was used daily. The ward rounds started at 09:00 hours every morning. The glycemic levels of the patients were reviewed during the rounds and insulin titration dose was determined by physicians according to the fasting BG (FBG) in the morning and 2-hour postprandial BG (2hBG) after breakfast of the present day and $2 \mathrm{hBG}$ after lunch and dinner in the day before.

\section{Insulin initiation}

All antidiabetic agents were discontinued on admission to the hospital. Insulin was started at a total daily dose (TDD) of 0.4 unit $/ \mathrm{kg}$. The patients in both groups received $50 \%$ of the TDD as glargine and $50 \%$ as aspart. Glargine was administered as a single daily dose while aspart was divided into three equal parts.

\section{Insulin titration}

Weight-based insulin titration

Glargine titration: 0.1 unit $/ \mathrm{kg} /$ day when $\mathrm{FBG}$ was over $7.8 \mathrm{mmol} / \mathrm{L}$.

Aspart titration: TDD of $0.1 \mathrm{unit} / \mathrm{kg} /$ day when $2 \mathrm{hBG}$ after each meal was $>10.0 \mathrm{mmol} / \mathrm{L}$, which was divided into three equal parts adding to three premeal boluses. If one $2 \mathrm{hBG}$ reached the target, the $1 / 3$ aspart was not titrated further (table 1).

\section{Glucose-based insulin titration}

The glucose level-based glargine and aspart dose titration algorithm were modified from Riddle $e t a t^{22}$ and Trence $e t$ $a l{ }^{23}$ respectively (table 2 ).

Five-point BG was measured, including FBG, 2hBG after three meals, and BG at 03:00 hour with a glucose meter (Accu-Chek Advantage; Roche Diagnostics, Basel, Switzerland). In addition, the glucose levels were measured whenever the patients reported symptoms of

\begin{tabular}{|c|c|c|c|}
\hline Glargine & & Aspart & \\
\hline $\begin{array}{l}\text { FBG } \\
\text { (mmol/L) }\end{array}$ & Titration dose & $\begin{array}{l}2 \mathrm{hBG} \\
(\mathrm{mmol} / \mathrm{L})\end{array}$ & Titration dose \\
\hline$\geq 7.8$ & +0.1 unit $/ \mathrm{kg}$ & $\geq 10.0$ & $+1 / 3 \times 0.1$ unit $/ \mathrm{kg}$ \\
\hline$<3.9$ & -0.1 unit/kg & $<3.9$ & -2 unit \\
\hline
\end{tabular}

FBG, fasting blood glucose; 2hBG, 2-hour postprandial blood glucose. 


\begin{tabular}{|c|c|c|c|}
\hline \multicolumn{2}{|l|}{ Glargine } & \multicolumn{2}{|l|}{ Aspart } \\
\hline $\begin{array}{l}\text { FBG } \\
\text { (mmol/L) }\end{array}$ & $\begin{array}{l}\text { Titration } \\
\text { dose (unit) }\end{array}$ & $\begin{array}{l}2 \mathrm{hBG} \\
(\mathrm{mmol} / \mathrm{L})\end{array}$ & $\begin{array}{l}\text { Titration } \\
\text { dose (unit) }\end{array}$ \\
\hline $7.8-8.9$ & +4 & $10.0-11.9$ & +1 \\
\hline $9.0-9.9$ & +6 & $12.0-13.9$ & +2 \\
\hline \multirow[t]{3}{*}{$\geq 10.0$} & +8 & $14.0-15.9$ & +4 \\
\hline & & $16.0-17.9$ & +6 \\
\hline & & $\geq 18.0$ & +8 \\
\hline$<3.9$ & -4 & $<3.9$ & -2 \\
\hline
\end{tabular}

FBG, fasting blood glucose; 2hBG, 2-hour postprandial blood glucose.

hypoglycemia. Hypoglycemia is classified into three levels (level 1: $3.0<\mathrm{BG}<3.9 \mathrm{mmol} / \mathrm{L}$; level 2: $\mathrm{BG}<3.0 \mathrm{mmol} / \mathrm{L}$; level 3: a severe event that requires assistance from another person for treatment of hypoglycemia) as recommended by ADA..$^{24}$ Nocturnal hypoglycemia is defined as a hypoglycemia event occurs between 00:01 and 05:59 hours. Laboratory tests, including basic biochemistry and hemoglobin A1c (HbAlc) levels, were performed (Bio-Rad, Hercules, California, USA) in all patients on day 2 of hospital admission. Target BG was set at FBG $<7.8 \mathrm{mmol} / \mathrm{L}$ and $2 \mathrm{hBG}<10.0 \mathrm{mmol} / \mathrm{L}$ as recommended by AACE and ADA. ${ }^{1}$

\section{Outcome measures}

The primary outcome of the study was the length of time for achieving glycemic targets (FBG and 2hBG). The secondary outcome included insulin dose for achieving

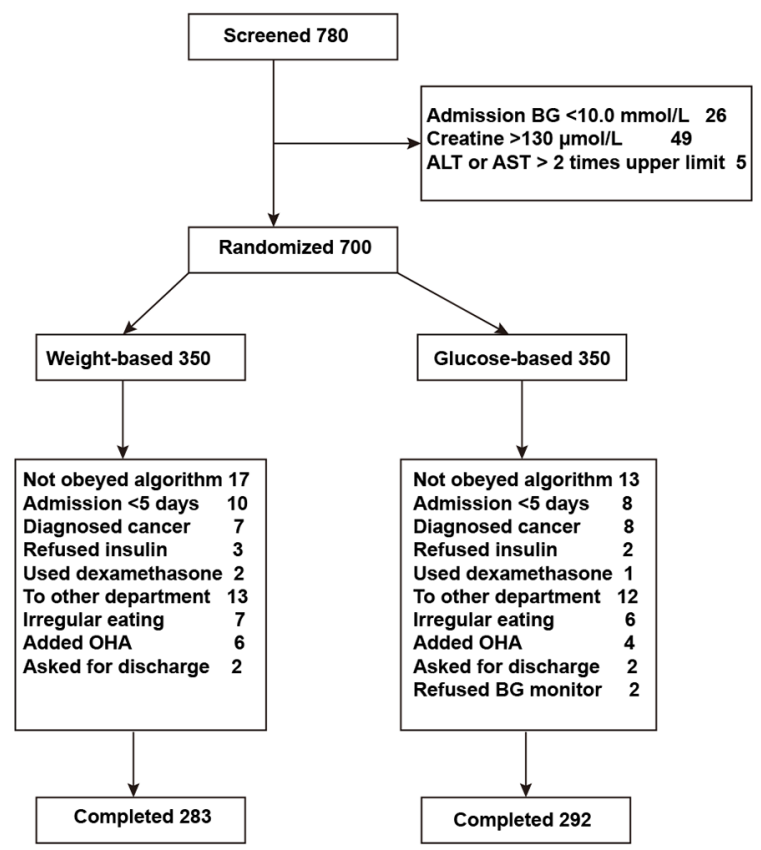

Figure 1 Study profile. ALT, alanine aminotransferase; AST, aspartate aminotransferase; BG, blood glucose; OHA, oral hypoglycemic agent. glycemic control and the incidence of hypoglycemia during hospitalization.

\section{Statistical analysis}

To estimate the sample size, we first conducted a separate preliminary study using 100 patients comparing the two algorithms. The patients were all consented. We consider it significant if the difference in the length of reaching BG targets is $>1$ day between two groups. According to $\mathrm{n} 1=\mathrm{kn} 2, \mathrm{n} 2=\left[\left(\mathrm{z}_{\alpha / 2}+\mathrm{z}_{\beta}\right)^{2} \sigma^{2}(1+1 / \kappa)\right] / \varepsilon^{2},{ }^{25}$ assuming all four points have significant difference and assuming $\alpha=0.05 \%$ and $80 \%$ power, the required number of patients for each group was 282 . To allow for a $20 \%$ dropout rate, we aimed to recruit a total of 700 patients.

\section{RESULTS}

Figure 1 shows the study profile. From January 2016 to June 2019, we screened 780 patients. Of these, 700 were included and were equally but randomly assigned to the weight-based and glucose-based groups. During hospitalization, 67 patients in the weight-based group and 58 in the glucose-based group dropped out. Therefore, data from 283 patients in the weight-based group and 292 patients in the glucose-based group were used for statistical analyses. As shown in table 3, both groups were well-matched for age, sex, body mass index (BMI) and glycemic levels. The distribution of previous antidiabetic treatments was also similar in two groups. The most common admission diagnoses were uncontrolled hyperglycemia and infections (table 3 ).

\section{Length of time for reaching BG targets}

The length of time for reaching the target of FBG, $2 \mathrm{hBG}$ after breakfast, lunch and dinner in weight-based group and glucose-based group was $2.93 \pm 1.49$ days vs $3.01 \pm 1.73$ days $(\mathrm{p}=0.548,95 \%$ CI -0.184 to 0.346$)$, $3.37 \pm 1.68$ days $\quad$ vs $3.52 \pm 1.78$ days $\quad(\mathrm{p}=0.283, \quad 95 \%$ CI -0.129 to 0.439$), \quad 3.81 \pm 1.91$ days vs $3.87 \pm 1.90$ days $(\mathrm{p}=0.690,95 \% \mathrm{CI}-0.254$ to 0.384$)$ and $3.90 \pm 1.79$ days vs $3.98 \pm 2.13$ days $(\mathrm{p}=0.617,95 \%$ CI -0.241 to 0.405 ), respectively (figure 2A). In the weight-based group, 7 patients had two points of BG and 14 patients had one point of BG that did not reach the targets. In the glucose-based group, 5 patients had two points of BG and 13 patients had one point of BG that did not reach the targets.

\section{Insulin dose}

The dose of glargine, prebreakfast aspart, prelunch aspart and predinner aspart in the weight-based group and the glucose-based group was $25.0 \pm 10.7$ unit/day vs $25.5 \pm 11.3 \mathrm{unit} /$ day $(\mathrm{p}=0.611,95 \% \mathrm{CI}-1.330$ to 2.262$)$, $11.2 \pm 5.3 \mathrm{unit} /$ day vs $11.8 \pm 6.2 \mathrm{unit} /$ day $(\mathrm{p}=0.245,95 \% \mathrm{CI}$ -0.384 to 1.501$), 12.1 \pm 6.3$ unit/day vs $12.4 \pm 6.1$ unit/day ( $\mathrm{p}=0.602,95 \% \mathrm{CI}-0.743$ to 1.282 ) and $12.0 \pm 5.2 \mathrm{unit} / \mathrm{day}$ vs $12.6 \pm 6.2$ unit/day ( $\mathrm{p}=0.216,95 \% \mathrm{CI}-0.347$ to 1.533 ), respectively (figure $2 \mathrm{~B}$ ). 
Table 3 Baseline characteristics

Weight-based Glucose-based

$(n=283) \quad(n=292)$

\begin{tabular}{|c|c|c|}
\hline \multicolumn{3}{|c|}{ Demographic characteristics } \\
\hline $\operatorname{Sex}(M, \%)$ & $168(59.4)$ & $168(57.5)$ \\
\hline Age (years) & $58.9(8.8)$ & $59.7(9.2)$ \\
\hline Diabetes duration (years) & $6.3(6.7)$ & $7.0(7.5)$ \\
\hline Weight (kg) & $64.4(11.4)$ & $65.5(11.8)$ \\
\hline BMI $\left(\mathrm{kg} / \mathrm{m}^{2}\right)$ & $24.4(3.9)$ & $24.7(3.9)$ \\
\hline \multicolumn{3}{|l|}{ Clinical characteristics } \\
\hline $\mathrm{HbA1c}(\%)$ & $10.9(2.4)$ & $11.1(2.5)$ \\
\hline C-peptide ( $\mu \mathrm{g} / \mathrm{L})$ & $2.2(2.1)$ & $2.0(1.1)$ \\
\hline Admission BG (mmol/L) & $17.9(5.3)$ & $18.6(5.4)$ \\
\hline \multicolumn{3}{|c|}{ Admission diagnosis (n, \%) } \\
\hline $\begin{array}{l}\text { Uncontrolled } \\
\text { hyperglycemia }\end{array}$ & $181(64.0)$ & $179(61.3)$ \\
\hline DK/DKA & $45(15.9)$ & $52(17.8)$ \\
\hline Pneumonia & $18(6.4)$ & $7(2.4)$ \\
\hline Urine tract infection & $24(8.5)$ & $28(9.6)$ \\
\hline Diabetic foot & $9(3.2)$ & $17(5.8)$ \\
\hline Other infections & $6(2.1)$ & $9(3.1)$ \\
\hline \multicolumn{3}{|c|}{ Previous diabetes treatment (n, \%) } \\
\hline None & $106(37.5)$ & $108(37.0)$ \\
\hline OHA or GLP-1RA & $95(33.6)$ & $97(33.2)$ \\
\hline One type & $25(8.8)$ & $24(8.2)$ \\
\hline Two types & $33(11.7)$ & $31(10.6)$ \\
\hline $\begin{array}{l}\text { Three or over three } \\
\text { types }\end{array}$ & $37(13.1)$ & $42(14.4)$ \\
\hline Insulin alone & $23(8.1)$ & $28(9.6)$ \\
\hline Both OHA and insulin & $38(13.4)$ & $37(12.7)$ \\
\hline
\end{tabular}

Values are $\mathrm{n}(\%)$ or mean (SD) unless otherwise stated. Other infection includes upper respiratory infection, skin ulcer and shingles.

$B G$, blood glucose; BMI, body mass index; DK, diabetic ketosis; DKA, diabetic ketoacidosis; GLP-1RA, glucagon-like peptide-1 receptor agonist; $\mathrm{HbA1c}$, hemoglobin $\mathrm{A} 1 \mathrm{c}$; $\mathrm{OHA}$, oral hypoglycemic agent.

\section{Hypoglycemia}

Episodes of hypoglycemia were experienced by $27.9 \%$ $(79 / 283)$ of patients in the weight-based group and $27.7 \%$ $(81 / 292)$ in the glucose-based group, most of which were level 1 hypoglycemic events. Three patients $(1.1 \%)$ in the weight-based group experienced level 2 hypoglycemia while six patients $(2.1 \%)$ in the glucose-based group experienced level 2 hypoglycemia $(\mathrm{p}=0.532)$ (figure 2C). Most of the hypoglycemic events occurred in the daytime (weight-based group: 61 patients, 21.6\%; glucose-based group: 62 patients, $21.2 \%$ ). Episodes of nocturnal hypoglycemia were experienced by $6.4 \%(18 / 283)$ of patients in the weight-based group and 6.5\% (19/292) in the glucosebased group ( $\mathrm{p}=0.943$ ). No severe hypoglycemic episode (level 3 hypoglycemia) occurred in either of the groups.
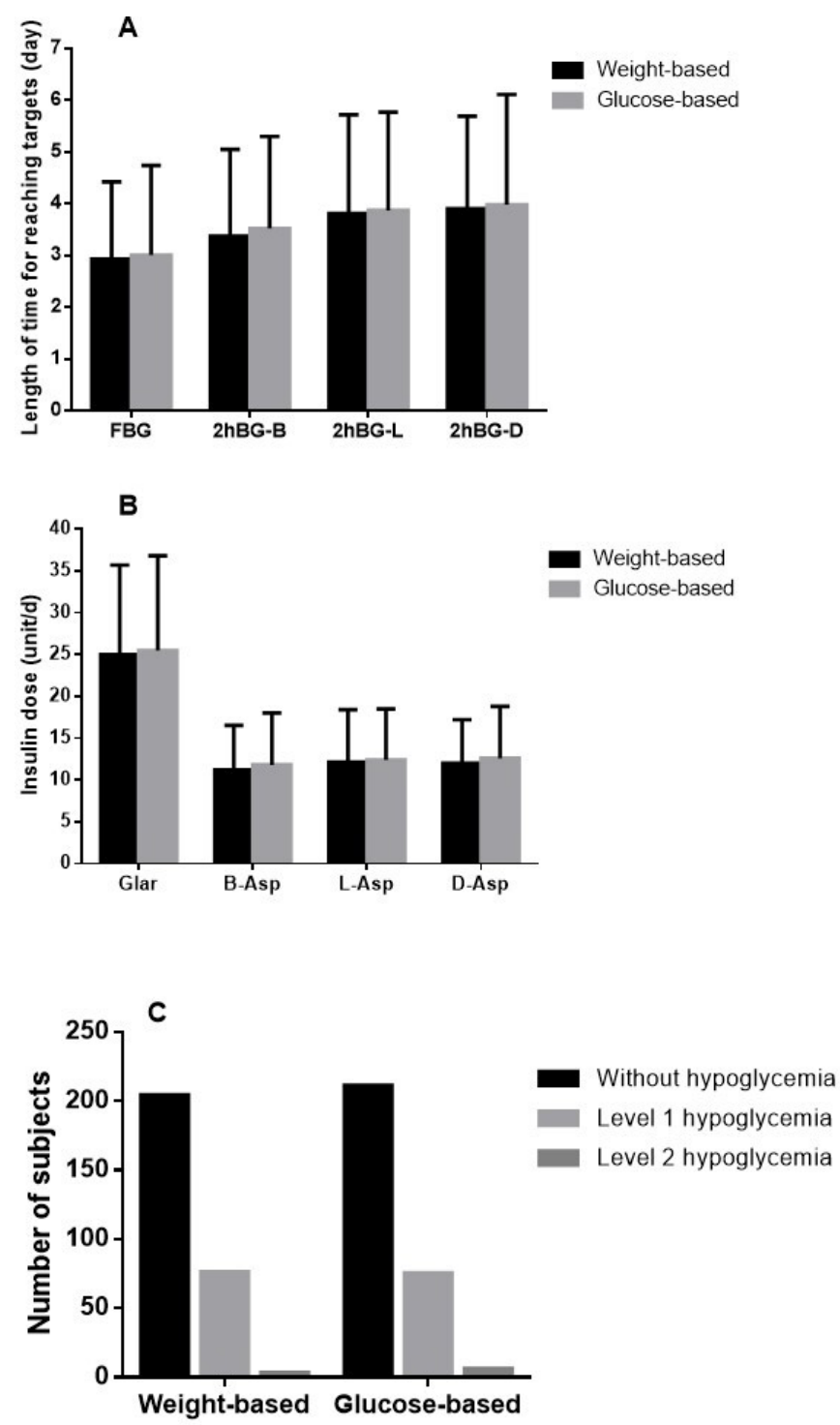

Figure 2 Outcomes of two groups. (A) Length of time for reaching glycemic targets. (B) Insulin dosage when reaching glycemic goals. (C) Incidence of hypoglycemia. Asp, aspart; B, breakfast; D, dinner; FBG, fasting blood glucose; Glar, glargine; 2hBG, 2-hour postprandial blood glucose; L, lunch.

\section{DISCUSSION}

In the present study, we demonstrated that using a weight-based insulin titration algorithm achieved the BG targets in the same period as using the glucose-based algorithm in hospitalized patients with poorly controlled T2DM. Both algorithms achieved 4-point BG targets in 4 days. Concurrently, the TDD was about 1 unit $/ \mathrm{kg} /$ day. This was higher than that reported by Liu et al, that is, 0.8 unit $/ \mathrm{kg} /$ day ${ }^{26}$ which included newly diagnosed patients receiving continual subcutaneous insulin infusion (CSII) treatment and had no stress condition.

Based on the physiological insulin secretion pattern, ${ }^{13}$ the TDD was divided as 1:1 for basal and three boluses at the initiation in this study. However, the ratio was about 2:3 in both groups at the end of interventions, which was similar to the study by Liu et al using $\mathrm{CSII}^{26}$ 
in newly diagnosed patients with T2DM. There were two explanations for this ratio (2:3). First, although aspart is known as a short-acting insulin, it is sufficient for $>5$ hours. ${ }^{27}$ The 'tail' contributes to basal insulin. Second, this corresponds to the carbohydrate supply of up to $67 \%$ of the total calories in the daily Chinese diet. ${ }^{28} \mathrm{~A}$ study conducted in the Latin American non-intensive care unit patients with T2DM using basal-bolus also showed a ratio of about 2:3 (glargine 22 unit/day and glulisine 31 unit/ day). ${ }^{16}$

Next, we analyzed the ratio of three boluses. Surprisingly, the three boluses were almost 1:1:1, although patients ingested different calories in three meals. Polonsky et al showed that the total amount of insulin secreted after each of the meals did not differ in both normal patients and patients with obesity, although patients consumed $20 \%$ of the total calories with breakfast and $40 \%$ with lunch and dinner, respectively. Similar quantities of insulin were secreted in response to each of the three meals. ${ }^{21}$ This phenomenon corroborated to the starting ratio of several basal-bolus trials, in which the three boluses were equal. ${ }^{7111415}$

In order to simplify our algorithm, we did not use correction insulin, although it was a standard part of the basal-bolus algorithm. ${ }^{1}$ Correction insulin was recommended by an expert consensus. However, few randomized clinical trials had evaluated the safety and efficacy of correcting mild hyperglycemia before meals and bedtime. ${ }^{14}$ Vellanki et al demonstrated that at least bedtime insulin correction for the treatment of mild-tomoderate hyperglycemia may not be necessary. ${ }^{14}$ Moreover, the correction insulin tries to retrospectively 'treat' rather than prospectively 'prevent' the hyperglycemia. ${ }^{29}$

Several theories have been put forth for fixed weightbased doses, which had similar effects as flexible glucosebased doses. First, weight represents insulin sensitivity. The heavier the person, the more likely he or she is to be insulin resistant. ${ }^{30}$ It has been found that obesity predicts a poor treatment response to insulin, irrespective of the insulin treatment algorithm, in patients with T2DM. ${ }^{31}$ Second, the administration of OHAs established a significant correlation between baseline $\mathrm{HbAlc}$ and decreased HbA1c. ${ }^{32} 33$ The present study showed that insulin also exhibited similar characteristics. A fixed insulin dose exerts different effects in patients with different baseline HbA1c levels. Third, hospitalized patients intake fixed amount of meals daily. Fourth, body weight decides the amount of meals intake and the amount one ingests. ${ }^{34}$

Hypoglycemia is one of the main concerns for antidiabetic treatment, especially for insulin. The incidence of hypoglycemia was similar between the two groups, and no severe hypoglycemia was found. In this regard, weightbased algorithm is proved to be safe for hospitalized patients with T2DM.

A recent survey found that practitioners were not comfortable with the use of insulin. ${ }^{35}$ To overcome clinical inertia, many tools, including electronic instrument, ${ }^{36}$ basal-bolus insulin therapy (BBIT) knowledge translation toolkit ${ }^{37}$ and 'insulin-on-board' calculators, ${ }^{38}$ are designed. Since the weight-based insulin titration protocol is not hard to remember and execute, we suggest that it may provide an effective tool for physicians, especially those not in the endocrinology department, to better control hyperglycemia.

In conclusion, we designed a weight-based insulin titration algorithm, which titrated fixed insulin dose daily The algorithm is equally effective and safe in hospitalized patients with T2DM compared with glucose-based algorithm.

Nevertheless, the present study has several limitations. First, all the included patients had regular diets. Therefore, whether the algorithm is suitable for patients with parenteral nutrition remains to be defined. Second, we did not compare our algorithm with the standard basal-bolus algorithm with correction insulin. Third, we initiated the protocol with basal-bolus $1: 1$ and ended with 2:3. Whether titration with basal-bolus 2:3 is better than $1: 1$ in the clinical setting needs to be investigated further by randomized clinical trials. Fourth, the subjects included in this study were from the same ethnic origin and the mean BMI values of these patients were relatively low $\left(<25 \mathrm{~kg} / \mathrm{m}^{2}\right)$. Finally, most patients in this study were admitted with uncontrolled hyperglycemia (mean HbA1c $>10 \%)$. Therefore, researches in other populations and in patients with relatively lower glycemic levels are required to further determine the efficacy of the new algorithm.

Acknowledgements The authors would like to thank Xinwang Wang for his help in statistics.

Contributors WL contributed to the study design and interpretation of data, and drafted the report. All authors contributed to study protocol discussion, data collection and writing the manuscript.

Funding This study was supported by National Natural Science Foundation of China (grant number 81800726).

Competing interests None declared.

Patient consent for publication Not required.

Ethics approval The study protocol and consent form were approved by the institutional review board of each participating institute (registration number 2015067).

Provenance and peer review Not commissioned; externally peer reviewed.

Data availability statement Data are available on reasonable request to Wangen Li, liwg660@126.com.

Open access This is an open access article distributed in accordance with the Creative Commons Attribution Non Commercial (CC BY-NC 4.0) license, which permits others to distribute, remix, adapt, build upon this work non-commercially, and license their derivative works on different terms, provided the original work is properly cited, appropriate credit is given, any changes made indicated, and the use is non-commercial. See: http://creativecommons.org/licenses/by-nc/4.0/.

\section{ORCID iDs}

Guangda Xiang http://orcid.org/0000-0002-6044-2308

Wangen Li http://orcid.org/0000-0002-1202-1576

\section{REFERENCES}

1 Moghissi ES, Korytkowski MT, DiNardo M, et al. American association of clinical endocrinologists and American diabetes association consensus statement on inpatient glycemic control. Diabetes Care 2009;32:1119-31. 
2 Wexler DJ, Meigs JB, Cagliero E, et al. Prevalence of hyper- and hypoglycemia among inpatients with diabetes: a national survey of 44 U.S. hospitals. Diabetes Care 2007;30:367-9

3 Boord JB, Greevy RA, Braithwaite SS, et al. Evaluation of hospital glycemic control at US academic medical centers. J Hosp Med 2009;4:35-44.

4 Umpierrez GE, Pasquel FJ. Management of inpatient hyperglycemia and diabetes in older adults. Diabetes Care 2017;40:509-17.

5 Kitabchi AE, Nyenwe E. Sliding-scale insulin: more evidence needed before final exit? Diabetes Care 2007;30:2409-10.

6 Cook CB, Castro JC, Schmidt RE, et al. Diabetes care in hospitalized noncritically ill patients: more evidence for clinical inertia and negative therapeutic momentum. J Hosp Med 2007;2:203-11.

7 Umpierrez GE, Smiley D, Zisman A, et al. Randomized study of basal-bolus insulin therapy in the inpatient management of patients with type 2 diabetes (rabbit 2 trial). Diabetes Care 2007;30:2181-6.

8 Davis S, Friece C, Roderman N, et al. Comparison of insulin detemir and insulin glargine for hospitalized patients on a basal-bolus protocol. Pharmacy 2017;5. doi:10.3390/pharmacy5020022. [Epub ahead of print: 23 Apr 2017].

9 Hochberg I. Managing diabetes in patients hospitalized in internal medicine units. Rambam Maimonides Med J 2018;9. doi:10.5041/ RMMJ.10334. [Epub ahead of print: 19 Apr 2018].

10 Howard JY, Watts SA. Bolus insulin prescribing recommendations for patients with type 2 diabetes mellitus. Fed Pract 2017;34:S26-31.

11 Umpierrez GE, Smiley D, Jacobs S, et al. Randomized study of basal-bolus insulin therapy in the inpatient management of patients with type 2 diabetes undergoing general surgery (rabbit 2 surgery). Diabetes Care 2011;34:256-61.

12 Inzucchi SE, Bergenstal RM, Buse JB, et al. Management of hyperglycemia in type 2 diabetes: a patient-centered approach: position statement of the American diabetes association (ADA) and the European association for the study of diabetes (EASD). Diabetes Care 2012;35:1364-79.

13 Umpierrez GE, Hellman R, Korytkowski MT, et al. Management of hyperglycemia in hospitalized patients in non-critical care setting: an endocrine Society clinical practice guideline. J Clin Endocrinol Metab 2012;97:16-38.

14 Vellanki P, Bean R, Oyedokun FA, et al. Randomized controlled tria of insulin supplementation for correction of bedtime hyperglycemia in hospitalized patients with type 2 diabetes. Diabetes Care 2015;38:dc141796-574.

15 Bellido V, Suarez L, Rodriguez MG, et al. Comparison of basal-bolus and premixed insulin regimens in hospitalized patients with type 2 diabetes. Diabetes Care 2015;38:2211-6.

16 Bueno E, Benitez A, Rufinelli JV, et al. BASAL-BOLUS regimen with insulin analogues versus human insulin in medical patients with type 2 diabetes: a randomized controlled trial in Latin America. Endocr Pract 2015;21:807-13.

17 King $A B$. No higher dose requirements with insulin detemir than glargine in type 2 diabetes: a crossover, double-blind, and randomized study using continuous glucose monitoring. J Diabetes Sci Technol 2010;4:151-4.

18 Li X, Du T, Li W, et al. Efficacy and safety of weight-based insulin glargine dose titration regimen compared with glucose level- and current dose-based regimens in hospitalized patients with type 2 diabetes: a randomized, controlled study. Clin Ther 2014;36:1269-75.

19 Zhang T, Lin M, Li W, et al. Comparison of the efficacy and safety of insulin Detemir and insulin Glargine in hospitalized patients with type 2 diabetes: a randomized crossover trial. Adv Ther 2016;33:178-85.
20 Galindo RJ, Davis GM, Fayfman M, et al. Comparison of efficacy and safety of glargine and DETEMIR insulin in the management of inpatient hyperglycemia and diabetes. Endocr Pract 2017;23:1059-66.

21 Polonsky KS, Given BD, Van Cauter E. Twenty-four-hour profiles and pulsatile patterns of insulin secretion in normal and obese subjects. J Clin Invest 1988;81:442-8.

22 Riddle MC, Rosenstock J, Gerich J, et al. The treat-to-target trial: randomized addition of glargine or human NPH insulin to oral therapy of type 2 diabetic patients. Diabetes Care 2003;26:3080-6.

23 Trence DL, Kelly JL, Hirsch IB. The rationale and management of hyperglycemia for in-patients with cardiovascular disease: time for change. J Clin Endocrinol Metab 2003;88:2430-7.

24 American Diabetes Association. 6. glycemic targets: tandards of medical care in diabetes-2020. Diabetes Care 2020;43:S66-76.

25 Chow SC, Shao J, Wang H. Sample size calculations in clinical research. New York, 2003.

26 Liu L, Ke W, Wan X, et al. Insulin requirement profiles of short-term intensive insulin therapy in patients with newly diagnosed type 2 diabetes and its association with long-term glycemic remission. Diabetes Res Clin Pract 2015;108:250-7.

27 Heise T, Pieber TR, Danne T, et al. A pooled analysis of clinical pharmacology trials investigating the pharmacokinetic and pharmacodynamic characteristics of fast-acting insulin aspart in adults with type 1 diabetes. Clin Pharmacokinet 2017;56:551-9.

28 Yang W, Liu J, Shan Z, et al. Acarbose compared with metformin as initial therapy in patients with newly diagnosed type 2 diabetes: an open-label, non-inferiority randomised trial. Lancet Diabetes Endocrinol 2014;2:46-55.

29 Hirsch IB, Paauw DS, Brunzell J. Inpatient management of adults with diabetes. Diabetes Care 1995;18:870-8.

30 Reaven GM. The metabolic syndrome: is this diagnosis necessary? Am J Clin Nutr 2006;83:1237-47.

31 Yki-Järvinen H, Ryysy L, Kauppila M, et al. Effect of obesity on the response to insulin therapy in noninsulin-dependent diabetes mellitus. J Clin Endocrinol Metab 1997;82:4037-43.

32 Bloomgarden ZT, Dodis R, Viscoli CM, et al. Lower baseline glycemia reduces apparent oral agent glucose-lowering efficacy: a meta-regression analysis. Diabetes Care 2006;29:2137-9.

$33 \mathrm{Ji} \mathrm{L,} \mathrm{Ma} \mathrm{J,} \mathrm{Li} \mathrm{H,} \mathrm{et} \mathrm{al.} \mathrm{Dapagliflozin} \mathrm{as} \mathrm{monotherapy} \mathrm{in} \mathrm{drug-naive}$ Asian patients with type 2 diabetes mellitus: a randomized, blinded, prospective phase III study. Clin Ther 2014;36:84-100.

34 Meldrum DR, Morris MA, Gambone JC. Obesity pandemic: causes, consequences, and solutions-but do we have the will? Fertil Steril 2017;107:833-9.

35 Cook CB, Zimmerman RS, Gauthier SM, et al. Understanding and improving management of inpatient diabetes mellitus: the Mayo clinic Arizona experience. J Diabetes Sci Technol 2008;2:925-31.

36 Wexler DJ, Shrader P, Burns SM, et al. Effectiveness of a computerized insulin order template in general medical inpatients with type 2 diabetes: a cluster randomized trial. Diabetes Care 2010;33:2181-3.

37 Helmle KE, Chacko S, Chan T, et al. Knowledge translation to optimize adult inpatient glycemic management with basal bolus insulin therapy and improve patient outcomes. Can J Diabetes 2018;42:505-13.

38 Neubauer KM, Mader JK, Höll B, et al. Standardized glycemic management with a computerized workflow and decision suppor system for hospitalized patients with type 2 diabetes on different wards. Diabetes Technol Ther 2015;17:685-92. 